\title{
Implementation of a Return to Work Strategy in Germany-Are There Changes in Work-Related Rehabilitation Measures and Employment Status in Chronic Conditions?
}

\author{
Cornelia Gerdau-Heitmann', Monika Schwarze ${ }^{2 *}$ \\ ${ }^{1}$ Abt. Technik und Gesundheit für Menschen (TGM), Jade Hochschule Oldenburg, Oldenburg, Germany \\ ${ }^{2}$ Klinik für Rehabilitationsmedizin, Medizinische Hochschule Hannover, Hanover, Germany \\ Email: "schwarze.monika@mh-hannover.de
}

Received 20 January 2016; accepted 26 February 2016; published 29 February 2016

Copyright (C) 2016 by authors and Scientific Research Publishing Inc.

This work is licensed under the Creative Commons Attribution International License (CC BY).

http://creativecommons.org/licenses/by/4.0/

(c) (i) Open Access

\begin{abstract}
Objectives: Aging workforces with increasing numbers of chronic conditions require health initiatives with greater workplace focus. A regional pension insurance introduced a Return To Work (RTW) strategy for insurants with chronic conditions. The objective was to identify the degree of implementation of work related measures in medical rehabilitation and the extent of RTW outcomes. Methods: 5883 insurants were considered. Severe Restriction of Work Ability (SRWA), Work-related Medical Rehabilitation (WMR), and Case Management (CM) were examined for 2008 and 2012. An Index of Employment status (IoE) was used in a logistic regression. Results: Utilization of WMR raised from $12.3 \%$ in 2008 to $66.1 \%$ in 2012 . The proportion of insurants with SRWA and WMR grew from $8 \%$ up to $40.1 \%$. In $2008,14.7 \%$ of insurants with SRWA received WMR; in 2012 , it grew to $76.6 \%$. On the other hand, in $201226 \%$ got WMR without SRWA and $12.2 \%$ had SRWA and got no WMR. CM was not conducted in 2008 but reached $20.2 \%$ in 2012 . Across all indications, WMR resulted in positive RTW as measured by IoE: OR = 0.75 (KI-95\%: $0.67-0.86)$. Conclusion: WMR was successfully implemented according to the German guideline. There is a need to optimize the linkage between SRWA and WMR and CM to provide need-based care.
\end{abstract}

\section{Keywords}

Chronic Conditions, Return to Work (RTW), Work-Related Medical Rehabilitation (WMR), Case Management (CM), Severe Restrictions of Work Ability (SRWA)

\footnotetext{
${ }^{*}$ Corresponding author.
}

How to cite this paper: Gerdau-Heitmann, C. and Schwarze, M. (2016) Implementation of a Return to Work Strategy in Germany-Are There Changes in Work-Related Rehabilitation Measures and Employment Status in Chronic Conditions? Open Journal of Therapy and Rehabilitation, 4, 55-66. http://dx.doi.org/10.4236/ojtr.2016.41005 


\section{Introduction}

Due to demographic changes-like those in many industrialized societies-Germany is facing a reduction and aging of the population [1] [2]. These population changes cause a rising prevalence of chronic conditions [3] [4]. They also impact the labor market, where companies are encountering massive challenges because of the moving age composition of the workforce [5] [6]. According to population projections, the amount of working age persons in Germany between 20 and 64 years was 49.2 million in 2013; by 2060 the amount will probably decrease between 34 and 38 million [2].

With a higher age, the incidence of chronic conditions rises [7] [8]; these influence the quality of life as well as work and earning capacity [9]. However, a suitable working ability is a key component of work life participation [10]. In regard to sick leave, chronic conditions often lead to high numbers and long duration. In particular, the numbers of people on sick leave for MSD are continually at a high level. In 2013, one fifth of sick leave in Germany was attributed to MSD (21.8\%), followed by respiratory diseases (13.4\%), mental illnesses (9.8\%), cardiovascular diseases (6.2\%) and diseases of the digestive organs (5.3\%) [11]. In addition, early retirement due to the incapacity to work is rising, particularly for people with psychosomatic disorders [12].

Therefore, government initiatives and employers, especially health care and social security, are creating new strategies to support continued participation and return to work for older persons and workers with disabilities or/and chronic conditions [6] [13] [14]. From a global perspective, the strategies are in accordance with the 2014-2021 action plan of the World Health Organization (WHO) to improve the health of all people with disabilities, including their work life participation [15].

Workplace orientated interventions have been developed and evaluated internationally and nationally over a long period. According to a meta-analysis of Waddell et al. (2008), the basic components for successful RTW are early intervention, cooperation of all stakeholders, multidisciplinary intervention, work-related measures as well as the combination of different measures rather than isolated measures [16]. It has been shown that stronger work-related rehabilitation has positive effects on vocational participation [17]-[21].

In the field of medical and vocational rehabilitation carried out by the German pension insurance, the focus on participation in work is defined by social law. Thus, concepts and interventions are largely work-related [22]. The theoretical foundation of this bio-social model of multidisciplinary rehabilitation is based on the concept of the International Classification of Functioning (ICF) [23]. The main spectrums of treated diseases covered by the pension insurance measures are musculoskeletal disorders (MSD), cardio-respiratory problems, cancer, and psychosomatic disorders. Concerning the allocation, there is strong evidence that only rehabilitants with SRWA profit from WMR. The appropriate patients can be identified through validated screening instruments [24]. In 2010, a Profile of Requirements (PoR) for WMR of the German Pension Insurance was first published for MSD; in 2012, after evaluation of its implementation, it was extended for all chronic conditions. These requirements describe standards and recommended amounts of work-related measures in medical rehabilitation. Implementation was first tested in a phase model and is now established nationwide [24]-[27].

Due to historical development and social law, the German health care system is divided into different health services sectors. Therefore, suitable management among the triangle of service providers, service payers and insurants are needed to provide demand-orientated and cost-effective health care for persons with health problems and chronic condition of working age [28].

The main focus of the pension insurance due to Germany's social laws is to sustain the ability to work and to sustain the population's earning capacity through medical and vocational rehabilitation measures for people with chronic conditions ( 9 Abs. 1 SGB VI). For this reason, as a central player, this insurance is predestined to play a coordinative and integrative role between the health system and other stakeholders who are addressing return to work. Last, the financial structure of the service provider is secured through contributions of their insurants. Therefore, an extended and healthy work life with an earning capacity and a gainful employment status is of high socioeconomic interest.

Based on these findings, the pension insurance developed a RTW ${ }^{1}$ strategy [29] [30]. This study aims to assess the implementation and outcome of this integrative model focusing on WMR and CM as essential interventions of the strategy.

The following questions were addressed:

1) How many insurants were recipients of the RTW intervention (WMR/CM with or without SRWA) in 2008 compared to 2012?

\footnotetext{
${ }^{1}$ In this study the term RTW is used as well in the context of a strategy, as an intervention and an outcome measure.
} 
2) Are there changes in RTW (employment status one year after rehabilitation) between the two observation periods?

3) What are the most important factors for a RTW?

\section{Methods}

\subsection{Design}

An observational retrospective study was conducted collecting data of 5883 insurants with chronic conditions in 2008 or in 2012. The group received inpatient medical rehabilitation and/or further RTW measures e.g. WMR. Provider of the RTW intervention was the regional statutory pension insurance Braunschweig-Hannover. In 2008 RTW as a comprehensive strategy was barely implemented ("historical control group") whereas in 2012 the implementation of the strategy was almost completed by the insurance provider.

We separately analyzed different groups out of the study sample. First we compared a group of working age rehabilitants in 2008 and another sample in the second half of 2012 concerning implementation and effect of the RTW strategy and intervention. In a second analysis, we took a closer look only on the impact of WMR. We built a sample of rehabilitants receiving WMR and rehabilitants not getting WMR (Figure 1).

\subsection{Intervention}

Due to regional conditions and partial autonomy in addition to the national requirements, it was possible to establish a comprehensive RTW strategy for the federal state of Lower-Saxony. Nevertheless, these initiatives are embedded in procedures performed on the federal level. The strategy implemented by the regional German Pension Insurance includes both a conceptual approach as well as practical implications.

RTW as strategy involves a large amount of stakeholder cooperation in all areas of the health system. Through networking, cooperation and inter-sectorial actions with e.g. companies, general practitioner and health insurances RTW of the insurants with chronic conditions is supported.

Within the scope of the RTW strategy, the pension insurance initiated RTW interventions in their own management, administration and rehabilitation clinics. WMR was implemented according to the federal guidelines of the German Pension Insurance for WMR. These are described in detail in the PoR [26] [27]. The requirements specify the numbers and amounts of work-related therapeutic modules that are necessary to meet the needs of rehabilitants with work ability restrictions to enable their return to work. The implementation of WMR is also combined with a need-oriented approach and is offered in three need-based levels. Level A consists of motivational groups and is offered for all rehabilitants. Level B is particularly for rehabilitants with SRWA and includes work-related diagnostics, on-the-job training and work-orientated patient education. Level C includes highly intensive offers for a small group of rehabilitants with SRWA, such as external vocational training.

To support the effectiveness of the work-related therapeutic services in rehabilitation centers, additional CM

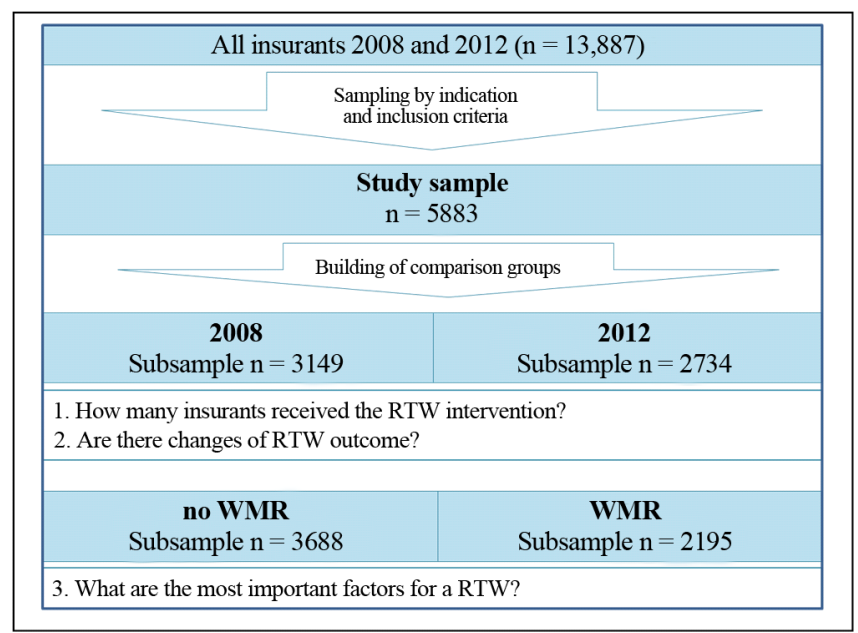

Figure 1. Study population and subsamples. 
as a further tool has been implemented. The CM program involves an individual case manager helping the insurant identify further obstacles for a return to work and their possible solutions. The person is given an individual action plan. During this process, the insurant's case manager contacts other caregivers to promote integrated care [31].

\subsection{Sample}

Patients were included if they received inpatient medical rehabilitation in 2008 or 2012. The considered diagnosis were musculoskeletal disorders (according to ICD M00 - M99), cardiovascular diseases (according to ICD I00 - I99), cancer (according to ICD C00 - D48) or psychosomatic disorders (according to ICD F00 - F09, F17, F20 - F45, F48 - F99). Insurants who were retired or received benefits due to reduced earning capacity were excluded, as were rehabilitants who received post-acute care.

Out of the total group of insurants with rehabilitation in 2008 and 2012, a total sample of 5883 insurants was included. A random sample was drawn for indications of musculoskeletal and psychosomatic disease. The complete sample was included for persons with cardiovascular disease and cancer because this group was too small for randomization.

In 2008, 3149 insurants fulfilled the inclusion criteria, and 2734 fulfilled the criteria in 2012. Table 1 shows both subsamples (2008 and 2012) by sex, age group, and indication. There were no differences regarding age ( $\mathrm{p}$-Value $>0.10$ ) or gender ( $\mathrm{p}$-Value $>0.23$ ).

\subsection{Data Sources}

Administrative data routinely produced for the insurance records was provided by the regional pension insurance. These data records include information on therapeutic services from the discharge report as well as socio-economic data. Data was available at three times: the years before, during and after medical rehabilitation.

We analysed person-related socio-economic data, discharge report information and employment status. The discharge report includes information regarding the work situation as well as the amount of work-related rehabilitation measures received during an inpatient stay.

Table 1. Distribution of sex, age group and indication.

\begin{tabular}{|c|c|c|c|c|c|c|c|c|c|c|}
\hline \multirow{3}{*}{ Age group (years) } & \multicolumn{10}{|c|}{ Male } \\
\hline & \multicolumn{5}{|c|}{2008} & \multicolumn{5}{|c|}{2012} \\
\hline & MD & $\mathrm{CV}$ & CA & PS & all & MD & $\mathrm{CV}$ & CA & PS & all \\
\hline$>15-25$ & 10 & 0 & 0 & 8 & 18 & 7 & 1 & 3 & 8 & 19 \\
\hline$>25-35$ & 53 & 7 & 8 & 25 & 93 & 49 & 1 & 6 & 39 & 95 \\
\hline$>35-45$ & 181 & 55 & 26 & 141 & 403 & 159 & 12 & 22 & 95 & 288 \\
\hline$>45-55$ & 305 & 186 & 83 & 147 & 721 & 360 & 90 & 41 & 149 & 640 \\
\hline$>55-65$ & 218 & 133 & 78 & 62 & 491 & 214 & 73 & 56 & 71 & 414 \\
\hline all & 767 & 381 & 195 & 383 & 1726 & 789 & 177 & 128 & 362 & 1456 \\
\hline \multirow{3}{*}{ Age group (years) } & \multicolumn{10}{|c|}{ Female } \\
\hline & \multicolumn{5}{|c|}{2008} & \multicolumn{5}{|c|}{2012} \\
\hline & MD & $\mathrm{CV}$ & $\mathrm{CA}$ & PS & all & MD & $\mathrm{CV}$ & CA & PS & all \\
\hline$>15-25$ & 8 & 0 & 1 & 11 & 20 & 13 & 0 & 1 & 11 & 25 \\
\hline$>25-35$ & 33 & 1 & 1 & 37 & 72 & 34 & 0 & 2 & 35 & 71 \\
\hline$>35-45$ & 175 & 12 & 42 & 109 & 338 & 125 & 2 & 17 & 75 & 219 \\
\hline$>45-55$ & 351 & 35 & 91 & 157 & 634 & 385 & 12 & 56 & 143 & 596 \\
\hline$>55-65$ & 187 & 38 & 68 & 66 & 359 & 229 & 8 & 51 & 79 & 366 \\
\hline \multirow[t]{2}{*}{ all } & 754 & 86 & 203 & 380 & 1423 & 786 & 22 & 127 & 343 & 1278 \\
\hline & \multicolumn{5}{|c|}{ Total 3149} & \multicolumn{5}{|c|}{ Total 2734} \\
\hline
\end{tabular}


All relevant general and work-related medical rehabilitation therapeutic services are documented via the classification of therapeutic services (KTL) [32]. CM services are documented separately in the rehabilitant's discharge report.

\subsection{Measurements}

To define SRWA, we used the indicators of work ability from the discharge report. As proposed by MüllerFahrnow and Radoschewski (2009), SRWA is determined if one of three criteria is fulfilled: 1 . inability to work for at least three months in the year before rehabilitation; 2. work ability in the last job under six hours; or 3. unemployment in the year before rehabilitation for at least three months [33].

The amount of WMR was measured by using the classification of therapeutic services (KTL) [32]. The WMR KTLs were separated to identify duration and frequency. The sum was calculated and categorized into different levels. According to the guidelines, levels A, B and C of WMR-Categories were defined. In this study, WMR was defined if a rehabilitant received level B or C. Information regarding the implementation of CM that was defined in CM was offered.

To measure whether a person returns to paid work after rehabilitation, an Index of Employment (IoE) was developed. The IoE indicates the degree of returning to work. To describe the index as precisely as possible, different variables were considered. Periods with employment, unemployment, sickness benefits or transitional allowances were included and recorded in days per year. Then all variables of the IoE were weighted by factors as follows: days with employment (1.0), days with sickness benefits or transitional payments (0.7), days with unemployment I (0.4), and days with unemployment II (Hartz IV) (0.1). Subsequently, the sum of all weighted periods was divided by the total number of days. This compounded IoE can take values from 0 to 1 . An IoE of 1 is associated with a high level of return to work.

\subsection{Data Analysis}

For the groups of insurants of 2008 and 2012, via a descriptive evaluation, we identified who received WMR and/or CM and whether there were differences between an insurant with SRWA and one without.

The IoE was calculated for each year for all participants before, during and after rehabilitation. The course of the two samples, 2008 and 2012, was compared.

To identify the influence of different parameters on returning to work (e.g., SRWA, WMR, CM, age, and sex), the median IoE of the year after rehabilitation was used in logistic regression models. Rehabilitants with WMR in 2008 and 2012 (subgroup with WMR) were compared with rehabilitants in 2008 and 2012 without this offer (subgroup without WMR). Odds ratios (OR) under 1 show that these factors reduce the risk of a negative IoE. Values over 1 indicate that these factors hinder rehabilitants regarding returning to work.

\section{Results}

\subsection{Comparison of RTW Interventions in the Observation Period}

The proportion of insurants with SRWA, WMR and CM are shown in Table 2. They are separated by period and indication. We also described subcategories of insurants with SWRA that received WMR or no WMR. And who had no SRWA and WMR.

\subsubsection{SRWA}

More than half of all rehabilitants in both observation periods suffered from SRWA. In 2008, 54.6\% had SRWA, and in 2012, the percentage was 52.3\%. The prevalence of SRWA differs between indications, with higher proportions in cancer and musculoskeletal disorders.

\subsubsection{WMR}

In 2008, 12.3\% of all rehabilitants received WMR; however, these were only patients with musculoskeletal disorders. In 2012, the percentage of rehabilitants with WMR increased in all indications (66.1\%), particularly for psychosomatic patients (97.4\%) (Table 2). We also found higher proportions of WMR for males than for females, except for rehabilitants with musculoskeletal disorders (data not shown). 
Table 2. Implementation of RTW Intervention (SRWA, WMR and CM).

\begin{tabular}{|c|c|c|c|c|}
\hline \multirow[t]{2}{*}{ Indication } & \multicolumn{2}{|c|}{2008} & \multicolumn{2}{|c|}{2012} \\
\hline & $\mathrm{n}$ & $\%$ & $\mathrm{n}$ & $\%$ \\
\hline \multicolumn{5}{|l|}{ Across indication } \\
\hline all & 3149 & 100.0 & 2734 & 100.0 \\
\hline Patients with SRWA & 1718 & 54.6 & 1429 & 52.3 \\
\hline and WMR & 253 & 8.0 & 1095 & 40.1 \\
\hline no WMR & 1465 & 46.5 & 334 & 12.2 \\
\hline Patients without SRWA & 1431 & 45.4 & 1305 & 47.7 \\
\hline and WMR & 135 & 4.3 & 712 & 26.0 \\
\hline Patients with WMR & 388 & 12.3 & 1807 & 66.1 \\
\hline Patients with CM & 0 & 0.0 & 553 & 20.2 \\
\hline \multicolumn{5}{|l|}{ Musculoskeletal Disorders } \\
\hline all & 1521 & 100 & 1575 & 100 \\
\hline Patients with SRWA & 833 & 54.8 & 888 & 56.4 \\
\hline and WMR & 253 & 16.6 & 726 & 46.1 \\
\hline no WMR & 580 & 38.1 & 162 & 10.3 \\
\hline Patients without SRWA & 688 & 45,2 & 45.2 & 43.6 \\
\hline and WMR & 135 & 8.9 & 285 & 18.1 \\
\hline Patients with WMR & 388 & 25.5 & 1011 & 64.2 \\
\hline Patients with CM & 0 & 0.0 & 343 & 21.8 \\
\hline \multicolumn{5}{|l|}{ Cardiovascular Diseases } \\
\hline all & 467 & 100.0 & 199 & 100.0 \\
\hline Patients with SRWA & 229 & 49.0 & 70 & 35.2 \\
\hline and WMR & 0 & 0.0 & 36 & 18.1 \\
\hline no WMR & 229 & 49.0 & 30 & 15.1 \\
\hline Patients without SRWA & 238 & 51.0 & 129 & 64,8 \\
\hline and WMR & 0 & 0.0 & 34 & 17.1 \\
\hline Patients with WMR & 0 & 0.0 & 66 & 33.2 \\
\hline Patients with CM & 0 & 0.0 & 17 & 8.5 \\
\hline \multicolumn{5}{|l|}{ Cancer } \\
\hline all & 398 & 100.0 & 255 & 100.0 \\
\hline Patients with SRWA & 283 & 71.1 & 174 & 68.2 \\
\hline and WMR & 0 & 0.0 & 38 & 14.9 \\
\hline no WMR & 283 & 71.1 & 136 & 53.3 \\
\hline Patients without SRWA & 115 & 28.9 & 81 & 31.8 \\
\hline and WMR & 0 & 0.0 & 5 & 2.0 \\
\hline Patients with WMR & 0 & 0.0 & 43 & 16.9 \\
\hline Patients with CM & 0 & 0.0 & 12 & 4.7 \\
\hline \multicolumn{5}{|l|}{ Psychosomatic Disorders } \\
\hline all & 763 & 100.0 & 705 & 100.0 \\
\hline Patients with SRWA & 373 & 48.9 & 297 & 42.1 \\
\hline and WMR & 0 & 0.0 & 295 & 41.8 \\
\hline no WMR & 373 & 48.9 & 2 & 0.3 \\
\hline Patients without SRWA & 390 & 51.1 & 408 & 57.9 \\
\hline and WMR & 0 & 0.0 & 392 & 55.6 \\
\hline Patients with WMR & 0 & 0.0 & 687 & 97.4 \\
\hline Patients with CM & 0 & 0.0 & 181 & 25.7 \\
\hline
\end{tabular}




\subsubsection{Linkage between SRWA and WMR}

Based on the total group of rehabilitants per year, the proportion of persons with SRWA and WMR grew from 8\% in 2008 up to $40.1 \%$ in 2012 (Table 2).

On the other hand in 2012 26\% got WMR without SRWA and 12.2\% had SRWA and got no WMR.

Looking at the subgroup of persons with SRWA (2008: $n=1718$; 2012: $n=1.429)$ as a reference following picture emerges. From 2008 to 2012 the proportion of rehabilitants with SRWA obtaining WMR increased from $14.7 \%$ up to $76.6 \%$.

Considering the subgroup of rehabilitants receiving WMR $(2008: \mathrm{n}=388 ; 2012: \mathrm{n}=1.807)$ the proportion of rehabilitants getting WMR without SRWA in 2008 was 34.8\%; whereas 39.4\% in 2012. There were great differences between the indications, with higher proportions particularly for rehabilitants with psychosomatic disorders; here, $57.1 \%$ of rehabilitants who received WMR had no SRWA and musculoskeletal disorders (28.2\%). Lower proportions can be observed in rehabilitants with cancer; $10.4 \%$ of those who received WMR had no SRWA (data not shown in tables).

\subsubsection{CM}

CM was initiated in 2012. For a total of 553 (20.2\%) rehabilitants, a case management service was recommended. The highest proportion of CM can be observed in the group of rehabilitants with psychosomatic disorders (25.7\%), followed by musculoskeletal disorders (21.8\%), cardiovascular disease (8.5\%) and cancer (4.7\%). Men received CM more often than women, except for musculoskeletal disorders.

\subsection{Course of Employment Status}

The course of employment status as a RTW indicator is shown for the two periods. The IoE decreases from the year before rehabilitation until the year of rehabilitation in both periods. In the first group 2008 (less RTW Strategy), the IoE is still decreasing the year after the rehabilitation, whereas in the insurants group in 2012 (implementation of the RTW Strategy), the IoE is increasing in the year after rehabilitation (Figure 2).

\subsection{Factors for Returning to Work}

Odds ratios (OR) under 1 show that the risk of a negative IoE is reduced. Values over 1 hinder rehabilitants regarding returning to work. In our study, we found that WMR across all indications has a positive effect on returning to work. WMR reduces the risk of a lower IoE $(\mathrm{OR}=0.75$; CI: $0.67-0.86)$. In contrast, SRWA has five times higher risk of a lower IoE (OR = 4.98; CI: 4.44 - 5.59). $\mathrm{CM}$ also shows a negative effect on the IoE (OR = 2.29; CI: 1.84 - 2.87). Regarding influences by sex on the IoE, there was a positive effect for men (OR = 0.66; CI: 0.59 - 0.74) and a negative effect for women (OR = 1.52; CI: $1.34-1.70)$. Most commonly, the rehabilitants in the middle age group had the highest benefit (OR $=0.58$; CI: $0.43-0.80$ ) (Figure 3 ).

\section{Discussion}

To meet demographic challenges and the burden of chronic diseases it is necessary to develop new processes and structures in the current health system [6] [34]. A regional German statutory pension fund recently addressed this major problem and introduced a RTW strategy. In this study, the degree of implementation and outcome of the strategy was analyzed.

\subsection{Implementation of RTW Intervention}

The results indicate that the RTW intervention was largely implemented in the observation period.

In both samples, we found that more than half of the insurants showed SRWA. Compared to other studies, our findings were higher (Table 2). A recent analysis of a representative rehabilitation sample across indications shows that the sum of SRWA overall indications was $40.7 \%$, with the highest prevalence in cancer (60.5\%) [35]. We also found the highest SRWA-prevalence of $68.2 \%$ for cancer. However, in this study, the SRWA criteria were slightly different from ours; therefore, the comparability is restricted.

In 2012 the amount of WMR measures was five times as high as 2008 and reaches $66.1 \%$. It can be assumed that in 2012 in administrative allocation centers and rehabilitation clinics of the pension insurance RTW interventions were implemented as planned. The proportion of rehabilitants with SRWA and WMR reached $40.1 \%$. 


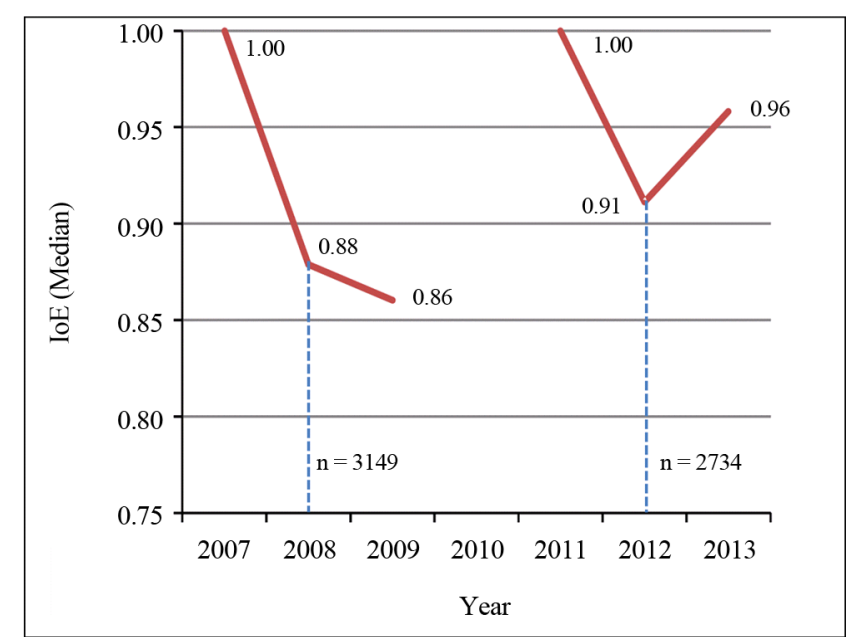

Figure 2. Course of Employment Status (IoE) of the samples of rehabilitants in 2008 and 2012.

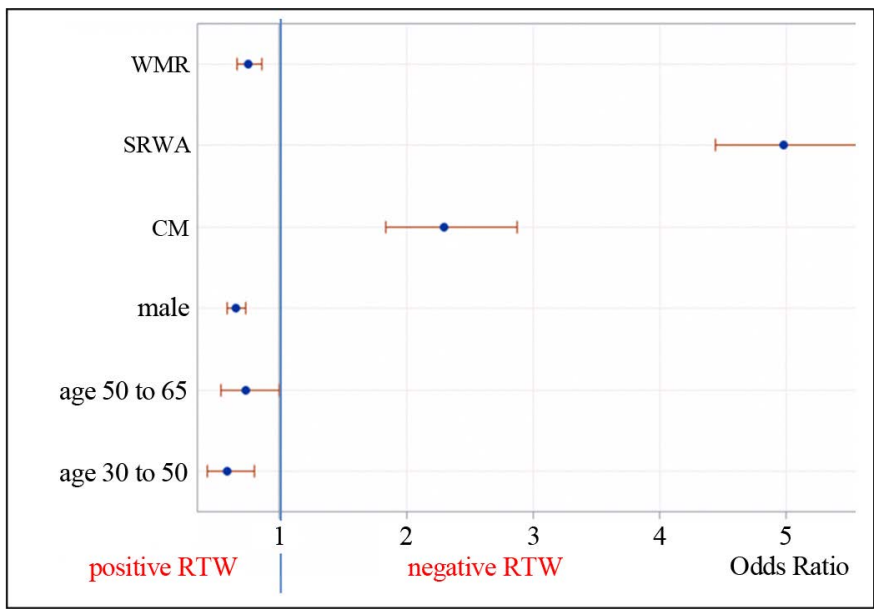

Figure 3. Factors influencing RTW using IoE (OR and 95\% confidence intervals).

This exceeds the proposed minimum requirements for WMR described in the PoR (WMR Level B: 30\%; WMR Level C: 5\%).

When it comes to the need-based matching of WMR and SRWA in 2012 the findings show a missing link. In 2012 e.g. 26\% got WMR without SRWA and 12.2\% had SRWA and got no WMR. This finding can be viewed as an over-, under- or misuse of WMR for insurants with and without SRWA. Different reasons for the overachievement of the proposed requirement for WMR for rehabilitants as well as the undersupply of WMR for rehabilitants without SRWA might play a role. It can be assumed that screening methods used to identify rehabilitants with SRWA in the rehab centers might be more sensitive than the discharge report criteria used in our study. Moreover, it cannot be ruled out that specific concepts in the clinics might play a more decisive role. A recent analysis conducted by Streibelt und Brünger (2014) concluded that the receipt of WMR might still largely dependent on the clinic concept [35]. Even more, the identification of the appropriate patients by validated screening instruments is of great importance because only rehabilitants with SRWA profit from WMR [22]. Particularly with regard to health costs and allocation of insurance capital, the linkage between insurants with SRWA and WMR should be optimized in the future.

CM was initiated only in the second period (2012). We found the highest proportion of CM in psychosomatic disorders. One explanation could be that in psychosomatic disorders, CM was developed and implemented primarily [31]. 


\subsection{Changes in Employment Status during the Observation Period}

During the course of chronic conditions, it can be expected that the prevalence of sick leave and the incapacity to work will increase. Consequently, due to sickness benefits, unemployment compensation, and transitional payments, the pension insurance does not receive the full contribution to its rehabilitation fund. After use of rehabilitation, health status and ability to work, and, therefore, contribution to the pension insurance fund, should increase again. In our findings, the IoE as an indicator decreases from the year before rehabilitation until the year of rehabilitation receipt in both periods. In the first period in 2008 (less RTW strategy), the IoE continues to decrease the year after rehabilitation, whereas in 2012 (implementation of the RTW strategy), the IoE increases during the post-rehabilitation year (Figure 2). This finding is assumed to be due to the effect of the almost full implementation of WMR. Another German study, which also focused on WMR and its effect on the contribution payments of psychosomatic rehabilitants, found that WMR has a positive effect only two years after rehabilitation [36]. Conversely, the possibility that other reasons are responsible cannot be excluded due to limitations in gathering a control group.

\subsection{Influences on Return to Work Outcome}

WMR has a protective effect on returning to work as expected. In contrast, SRWA has a negative influence on the IoE (Figure 3). This confirms that those rehabilitants need WMR. The impact of CM on the IoE was negative in this study. This finding may be due to the implementation phase, which was excessively short in our observation period. Regarding the IoE, we observed a protective effect for males and a negative effect for females. One reason for this effect could be observed in the different labor force participation rates of men and women in Germany. In addition, women are more often affected by a working situation in an atypical employment relationship. This leads to a generally higher risk regarding unemployment, but particularly for people with disability. Concerning age, most commonly rehabilitants in the middle age group (30 to 50 years) had the highest benefit compared to the youngest age group. The oldest group had less benefit regarding the IoE. This is in accordance with general lower participation rates at the labor market for older people. Furthermore, the prevalence of chronic disease is also increasing with age.

\subsection{Implications of the RTW Strategy}

A successful RTW program interchangeable vocational rehabilitation positively influences the potential labor force. Nevertheless, it depends on the economic situation if an enhanced potential is exploited. In a weak economic situation e.g. economic crises in 2009 with a high rate of unemployment, the chance of RTW for individuals with chronic disease might be lower. In this case, even a successful RTW strategy would have little effect. This could be an explanation for the lower IoE in 2009 of the insurants who received WMR in 2008 compared to the higher IoE of the insurants in 2013 who received WMR in 2012.

Coordinated reintegration initiatives like the described RTW strategy are more useful and are recommended compared to isolated measures. They also intend a fair allocation of health related measures and distribution of the costs for all social security institutions in the system. For medical insurance companies in Germany, it could mean to extend prevention and early intervention for patients with chronic conditions; especially for individuals in risk of losing their earning capacity. This is associated with higher costs in the first place. In the long run, however this could prevent and save costs-e.g. intensive rehabilitation measures. A weakness even of a coordinated strategy across social systems could be that the guiding lies in one hand instead of a neutral service center [28]. Moreover effective individual CM could provoke high costs for the pension insurance. Therefore, the evaluation of cost-effectiveness should be a subject in future studies.

\section{Strengths and Limitations}

This study has certain limitations. The meaningfulness of the results is limited because the available sample size was lower than the planned calculated sample size estimation. However, the random drawing of the sample from the main indications of MSD and psychosomatic disorders was as accurate as possible. Therefore, here a selection bias can be excluded. In addition, we could not develop a concomitant control group because of the already widely spread intervention programme. Therefore, we consider data from rehabilitants of the year 2008 which could be seen as a historical control group. 
In general, the comparison of the outcome of different RTW programs is difficult because used instruments in studies differ greatly. Moreover, there is no single outcome parameter to measure because RTW is a complex parameter [37].

As in our study in which RTW outcomes are measured only by administratively based data, the perspective of workers and other stakeholders is not included [38]. To include other measures such as reasons for no RTW attempts could be revealing, and a more comprehensive understanding could be provided [38]. Nevertheless, the secondary routinely produced data used in our study is complete and important. As postulated by the action plan of the WHO, available data should be used for health services research regarding rehabilitation [39].

\section{Conclusion}

The implementation of RTW strategy was successfully established. The degree of fulfillment of WMR has increased over the time of observation. WMR as a significant component of the RTW strategy has a high impact on return to work, which is demonstrated by the positive development of the employment status. To clarify whether the effect is due to WMR, further studies, such as randomized controlled trials, should be conducted. Further investigations should also focus on a tailored matching of WMR and SRWA because there only is evidence that insurants with SRWA are benefiting from WMR.

\section{Ethical considerations}

The study was approved by the Ethics Committee of the Hannover Medical School, Germany.

This article does not contain any studies with human participants performed by any of the authors.

For this type of study, formal consent is not required.

\section{Acknowledgements}

This paper is based on a project supported by the German Pension Insurance. The authors fondly thank Prof. Dr. Christoph Gutenbrunner for his support and Prof. Dr. Matthias Bethge for his valuable input. The German Pension Insurance Braunschweig-Hannover we thank for providing the data used.

\section{Conflicts of Interest}

From the authors of this study no conflicts of interest are reported.

\section{References}

[1] Anderson, G.F. and Hussey, P.S. (2000) Population Aging: A Comparison among Industrialized Countries. Health affairs, 19, 191-203. http://dx.doi.org/10.1377/hlthaff.19.3.191

[2] Statistisches Bundesamt, Ed. (2015) Bevölkerung Deutschlands bis 2060. 13. koordinierte Bevölkerungsvor ausberechnung. Statistisches Bundesamt, Wiesbaden.

[3] Alwan, A. (2011) Global Status Report on Noncommunicable Diseases 2010. World Health Organization, Geneva.

[4] Beaglehole, R., Bonita, R., Horton, R., Adams, C., Alleyne, G., Asaria, P., et al. (2011) Priority Actions for the Non-communicable Disease Crisis. The Lancet, 377, 1438-1447. http://dx.doi.org/10.1016/S0140-6736(11)60393-0

[5] Hertel, G. and Zacher, H. (in Press) Managing the Aging Workforce. In: Viswesvaran, C., Anderson, N., Ones, D.S., and Sinangil, H.K., Eds., The SAGE Handbook of Industrial, Work, \& Organizational Psychology, 2nd Edition, Volume 3, Sage Thousand Oakes, CA.

[6] Szinovacz, M.E. (2011) Introduction: The Aging Workforce: Challenges for Societies, Employers, and Older Workers. Journal of Aging and Social Policy, 23, 95-100. http://dx.doi.org/10.1080/08959420.2011.555185

[7] Blokstra, A., Baan, C., Boshuizen, H., Feenstra, T., Hoogenveen, R., Picavet, H., Smit, H., Wijga, A. and Verschuren, W., Eds. (2007) Impact of the Ageing Population on Burden of Disease. Projections of Chronic Disease Prevalence for 2005-2025. Vergrijzing en toekomstige ziektelast. Prognose chronische ziektenprevalentie 2005-2025. National Institute for Public Health and the Environment (RIVM), Eindhoven.

[8] Bhattacharya, J., Choudhry, K. and Lakdawalla, D. (2008) Chronic Disease and Severe Disability among Working-Age Populations. Medical Care, 46, 92-100. http://dx.doi.org/10.1097/MLR.0b013e3181484335

[9] De Jong, M., de Boer, A.G., Tamminga, S.J. and Frings-Dresen, M.H. (2015) Quality of Working Life Issues of Em- 
ployees with a Chronic Physical Disease: a Systematic Review. Journal of Occupational Rehabilitation, 25, 182-196. http://dx.doi.org/10.1007/s10926-014-9517-6

[10] Ilmarinen, J. (2006) The Ageing Workforce-Challenges for Occupational Health. Occupational Medicine. Occupational Medicine, 56, 362-364. http://dx.doi.org/10.1093/occmed/kql046

[11] Badura, B., Ducki, A., Schröder, H., Klose, J. and Meyer, M., Eds. (2014) Fehlzeiten-Report 2014: Erfolgreiche Unternehmen von morgen-gesunde Zukunft heutegestalten. Springer-Verlag, Berlin Heidelberg. http://dx.doi.org/10.1007/978-3-662-43531-1

[12] Wedegärtner, F., Arnhold-Kerri, S., Sittaro, N.A., Bleich, S., Geyer, S. and Lee, W.E. (2013) Depression- and Anxiety-Related Sick Leave and the Risk of Permanent Disability and Mortality in the Working Population in Germany: A Cohort Study. BMC Public Health, 13, 145. http://dx.doi.org/10.1186/1471-2458-13-145

[13] Berecki-Gisolf, J., Clay, F.J., Collie, A. and McClure, R.J. (2012) The Impact of Aging on Work Disability and Return to Work: Insights from Workers' Compensation Claim Records. Journal of Occupational and Environmental Medicine, 54, 318-327. http://dx.doi.org/10.1097/JOM.0b013e31823fdf9d

[14] Smith, M.L., Wilson, M.G., DeJoy, D.M., Padilla, H., Zuercher, H., Corso, P., Vandenberg, R., Lorig, K. and Ory, M.G. (2015) Chronic Disease Self-Management Program in the Workplace: Opportunities for Health Improvement. Frontiers in Public Health, 2, 179. http://dx.doi.org/10.3389/fpubh.2014.00179

[15] World Health Organization (2013) Global Action Plan for the Prevention and Control of Noncommunicable Diseases 2013-2020. World Health Organization, Geneva.

[16] Waddell, G., Burton, A.K. and Kendall, N.A. (2008) Vocational Rehabilitation—What Works, for Whom, and When? Report for the Vocational Rehabilitation Task Group, TSO, London.

[17] Bethge, M. and Müller-Fahrnow, W. (2008) Wirksamkeit einer intensivierten stationären Rehabilitation bei muskuloskelettalen Erkrankungen: systematischer Review und Meta-Analyse. Rehabilitation, 47, 200-209. http://dx.doi.org/10.1055/s-2008-1077091

[18] Schaafsma, F.G., Whelan, K., van der Beek, A.J., van der Es-Lambeek, L.C., Ojajärvi, A. and Verbeek, J.H. (2013) Physical Conditioning as Part of a Return to Work Strategy to Reduce Sickness Absence for Workers with Back Pain. Cochrane Database of Systematic Reviews, No. 8, 1-97. http://dx.doi.org/10.1002/14651858.CD001822.pub2

[19] Schonstein, E., Kenny, D.T., Keating, J.L. and Koes, B.W. (2003) Work Conditioning, Work Hardening and Functional Restoration for Workers with Back and Neck Pain. Cochrane Database of Systematic Reviews, No. 3, 1-63. http://dx.doi.org/10.1002/14651858.cd001822

[20] Streibelt, M. and Bethge, M. (2014) Effects of Intensified Work-Related Multidisciplinary Rehabilitation on Occupational Participation: A Randomized-Controlled Trial in Patients with Chronic Musculoskeletal Disorders. International Journal of Rehabilitation Research, 37, 61-66. http://dx.doi.org/10.1097/MRR.0000000000000031

[21] Wåhlin, C., Ekberg, K., Persson, J., Bernfort, L. and Öberg, B. (2012) Association between Clinical and Work-Related Interventions and Return-to-Work for Patients with Musculoskeletal or Mental Disorders. Journal of Rehabilitation Medicine, 44, 355-362. http://dx.doi.org/10.2340/16501977-0951

[22] Egner, U., Schliehe, F. and Streibelt, M. (2011) MBOR-Ein Prozessmodell in der medizinischen Rehabilitation (Work Related Medical Rehabilitation, MBOR_A Process Model in Medical Rehabilitation). Die Rehabilitation, 50, $143-144$. http://dx.doi.org/10.1055/s-0031-1277170

[23] World Health Organization (2001) International Classification of Functioning, Disability and Health: ICF. World Health Organization, Geneva.

[24] Bethge, M., Löffler, S., Schwarz, B., Vogel, H., Schwarze, M. and Neuderth, S. (2013) Gelingt die Umsetzung des Anforderungsprofils zur Durchführung der medizinisch-beruflich orientierten Rehabilitation? (Is the Guideline for Work-Related Medical Rehabilitation Successfully Implemented?) Rehabilitation, 53, 184-190. http://dx.doi.org/10.1055/s-0033-1353192

[25] Bethge, M., Löffler, S., Schwarz, B., Vogel, H., Schwarze, M. and Neuderth, S. (2014) Besondere berufliche Problemlagen: Spielen sie eine Rolle beim Zugang in die medizinisch-beruflich orientierte Rehabilitation? (Specific Work-Related Problems: Do They Matter in Access to Work-Related Medical Rehabilitation?) Rehabilitation, 53, 4955. http://dx.doi.org/10.1055/s-0033-1341459

[26] Deutsche Rentenversicherung (2012) Anforderungsprofil zur Durchführung der Medizinisch-beruflich orientierten Rehabilitation (MBOR) im Auftrag der Deutschen Rentenversicherung. Deutsche Rentenversicherung Bund, Berlin.

[27] Streibelt, M. and Buschmann-Steinhage, R. (2011) Ein Anforderungsprofil zur Durchführung der medizinischberuflich orientierten Rehabilitation aus der Perspektive der gesetzlichen Rentenversicherung. (A Profile of Requirements for the Performance of Work Related Medical Rehabilitation from the Perspective of the Statutory Pension Insurance). Rehabilitation, 50, 160-167. http://dx.doi.org/10.1055/s-0031-1275721

[28] Nürnberger, I. (2013) Das Rehabilitationssystem in Deutschland. Was gut läuft, wo es hakt und was sich ändern muss. 
Soziale Sicherheit, 62, 125-131.

[29] Gerdau-Heitmann, C., Gutenbrunner, C., Miede, J. and Schwarze, M. (2014) Umsetzung des Erwerbsbezugs in der medizinischen Rehabilitation-Analyse von Routinedaten der Deutschen Rentenversicherung Braunschweig-Hannover. Physikalische Medizin, Rehabilitationsmedizin, Kurortmedizin, 24, A5. http://dx.doi.org/10.1055/s-0034-1386584

[30] Schwarze, M., Ehlebracht-König, I., Kobelt, A., Rodewald, J., Gutenbrunner, C. and Miede, J. (2014) Strategie zur beruflichen (Re-) Integration aus Perspektive eines regionalen Rentenversicherungsträgers. Physikalische Medizin, Rehabilitationsmedizin, Kurortmedizin, 24, A25. http://dx.doi.org/10.1055/s-0034-1386604

[31] Piegza, M., Schwarze, M., Petermann, F. and Kobelt, A. (2013) Fallmanagement als innovativer Ansatz in der medizinisch-psychosomatischen Rehabilitation. Physikalische Medizin, Rehabilitationsmedizin, Kurortmedizin, 23, 348-352. http://dx.doi.org/10.1055/s-0033-1358743

[32] Deutsche Rentenversicherung Bund (2007) Klassifikation therapeutischer Leistungen in der medizinischen Rehabilitation (KTL). Deutsche Rentenversicherung Bund, Berlin.

[33] Müller-Fahrnow, W. and Radoschewski, F.M. (2009) Grundlagen. In: Hillert, A., Müller-Fahrnow, W. and Radoschewski, F.M., Eds., Medizinisch-beruflich orientierte Rehabilitation. Grundlagen und klinische Praxis, Deutscher Ärzte-Verlag, Köln, 1-14.

[34] Börsch-Supan, A. and Chiappori, P. (1991) Aging Population: Problems and Policy Options in the US and Germany. Economic Policy, 6, 104-139. http://dx.doi.org/10.2307/1344450

[35] Streibelt, M. and Brünger, M. (2014) Wie viele arbeitsbezogene Leistungen bekommen Patienten mit besonderen beruflichen Problemlagen? Analyse einer repräsentativen indikationsübergreifenden Stichprobe von Rehabilitanden. (How Many Work-Related Therapeutic Services Do Patients with Severe Restrictions of Work Ability Receive? Analysis of a Representative Rehabilitation Sample across Indications). Rehabilitation, 53, 369-375. http://dx.doi.org/10.1055/s-0034-1375643

[36] Jankowiak, S., Kaluscha, R., Holstiege, J. and Krischak, G. (2014) Evaluation unterschiedlicher Modelle medizinischberuflich-orientierter Rehabilitation in Baden-Württemberg (Eva-MBOR-BW)—Ergebnisse einer psychosomatischen Rehabilitationsklinik. In: Deutsche Rentenversicherung Bund, Ed., DRV-Schriften, 103, Berlin, 61-63.

[37] Vogel, A.P., Barker, S.J., Young, A.E., Ruseckaite, R. and Collie, A. (2011) What Is Return to Work? An Investigation into the Quantification of Return to Work. International Archive of Occupational Environmental Health, 84, 675-682. http://dx.doi.org/10.1007/s00420-011-0644-5

[38] Young, A.E., Besen, E. and Choi, Y. (2014) The Importance, Measurement and Practical Implications of Worker’s Expectations for Return to Work. Disability and Rehabilitation, 37, 1-9. http://dx.doi.org/10.3109/09638288.2014.979299

[39] Gutenbrunner, C. (2014) The WHO Action Plan "Better Health for Persons with Disabilities”: Consequences for Physical and Rehabilitation Medicine. Annals of Physical and Rehabilitation Medicine, 57, e393. http://dx.doi.org/10.1016/j.rehab.2014.03.1429 